\title{
Blackbox for Passive Measurement of MEASUREMENT DATA IN VEHICLES
}

\author{
BUMERL-LEXA, R. \& KUBINGER, W.
}

Abstract: A concept for a Controller Area Network (CAN) and European Onboard Diagnostic (OBD-2/EOBD) monitoring and recording embedded device, a black box, is described in this paper. It is designed to log data. This data contains speed, acceleration, or specific information from Anti-Blocking-System (ABS) or Electronic Stability Program (ESP). The interfaces as well as the hardware and software architecture, based on a Digital Signal Processor (DSP), are described. The Blackbox is designed for passive recording only. Therefore, the in-vehicle communication networks are not affected by this device. The Blackbox can be used in most vehicles with CAN-based control units. A typical application of the Blackbox is the collection of time-stamped dynamics data over a longer time period. The recorded information can be transferred to a PC for a later analysis. Future developments will include a video-capture option.

Key words: recording, CAN, OBD, passive, network, automotive, embedded
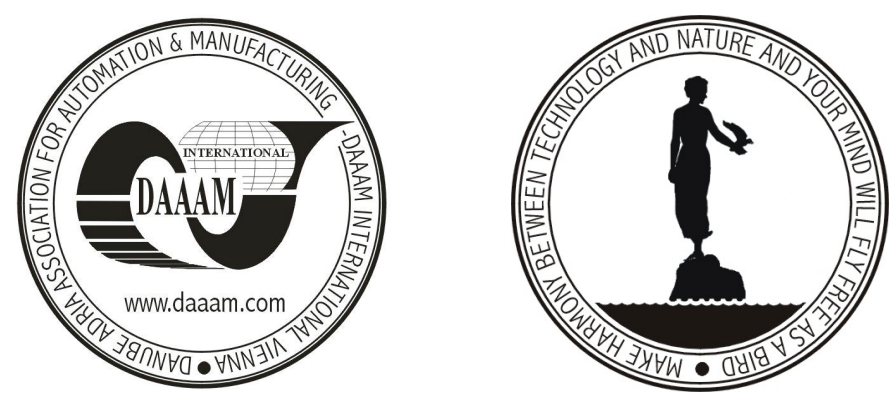

Authors' data: Dipl. Ing. Bumerl-Lexa R.[oman], Dr. Kubinger W.[ilfried], ARC Seibersdorf research GmbH Vienna, Austria, roman.bumerl-lexa@arcs.ac.at, wilfried.kubinger@arcs.ac.at

This Publication has to be referred as: Bumerl-Lexa, R. \& Kubinger, W. (2006). Blackbox for Passive Measurement of Measurement Data in Vehicles, Chapter 10 in DAAAM International Scientific Book 2006, B. Katalinic (Ed.), Published by DAAAM International, ISBN 3-901509-47-X, ISSN 1726-9687, Vienna, Austria DOI: $10.2507 /$ daaam.scibook.2006.10 